\title{
BMJ Open Can certified health professionals treat obesity in a community-based programme? A quasi-experimental study
}

\author{
Baukje Miedema, ${ }^{1}$ Stacey A Reading, ${ }^{2}$ Ryan A Hamilton, ${ }^{3}$ Katherine S Morrison, ${ }^{1}$ \\ Ashley E Thompson ${ }^{1}$
}

To cite: Miedema B, Reading SA, Hamilton RA, et al. Can certified health professionals treat obesity in a community-based programme? A quasiexperimental study. BMJ Open 2015:5:e006650. doi:10.1136/bmjopen-2014006650

- Prepublication history for this paper is available online. To view these files please visit the journal online (http://dx.doi.org/10.1136/ bmjopen-2014-006650).

Received 16 September 2014 Revised 8 December 2014 Accepted 9 December 2014

CrossMark

For numbered affiliations see end of article.

Correspondence to Dr Baukje Miedema; Baukje. Miedema@horizonnb.ca

\section{ABSTRACT}

Objective: To test the effectiveness of a nonpharmaceutical programme for obese participants in a rural Eastern Canadian Province using certified health professionals.

Design: A prospective quasi-experimental design with repeated premeasure and postmeasure.

Participants: 146 participants with obesity (body mass index $>30 \mathrm{~kg} / \mathrm{m}^{2}$ ) from rural and urban communities in an Eastern Canadian Province were divided into four groups.

Intervention: A 6-month intensive active communitybased lifestyle intervention (InI) delivered by Certified Exercise Physiologists, Certified Personal Trainers and Registered Dietitians, followed by 6 months of selfmanagement. A second intervention (InII) was nested in Inl and consisted of group-mediated cognitivebehavioral intervention (GMCBI) delivered by an exercise psychologist to two of the four Inl groups.

Outcomes: (1) Improving health outcomes among the participants' preactive and postactive 6-month intervention and self-management period, (2) Documenting the impact of InII (GMCBI) and location of the intervention (urban vs rural).

Results: The 6-month active Inl significantly improved cardiovascular health for participants who completed the intervention. InII (GMCBI) significantly lowered the attrition rate among the participants. The selfmanagement period was challenging for the participants and they did not make further gains; however, most were able to maintain the gains achieved during the active intervention. The location of the intervention, urban or rural, had little impact on outcomes.

Conclusions: A community-based programme utilising healthcare professionals other than physicians to treat obese patients was effective based on premeasure and postmeasure. During the self-management phase, the participants were able to maintain the gains.

Psychological support is essential to participant retention.

\section{BACKGROUND}

When people grow older, they engage less in physical activity. ${ }^{1}$ This often results in weight gain to obesity, defined as having a body

\section{Strengths and limitations of this study}

- Using self-referred participants for preintervention and postintervention may introduce sampling biases.

- More women than men participated in the intervention.

- A 6-month community-based active lifestyle intervention led by certified health professionals can be an effective way of treating obesity.

- Gains made during the active intervention were maintained during the 6 months of selfmanagement.

mass index (BMI) of $30 \mathrm{~kg} / \mathrm{m}^{2}$ or higher. ${ }^{2}$ The prevalence of obesity globally has increased steadily over the past few decades. $^{3}{ }^{4}$ A 1985 Canadian Health Promotion study reported that $6.1 \%$ of Canadian adults were found to be obese, as compared with $18.1 \%$ in $2010 .{ }^{5}{ }^{6}$ Some studies link obesity to higher levels of multiple chronic and mental health conditions and physical challenges. ${ }^{7-12}$ Hence, it is important that adults and specifically older adults who are overweight or obese attempt to become fitter to avoid or delay the onset of chronic disease.

Obesity is a multifaceted problem that defies magic bullet solutions often touted by popular media reporting (eg, extreme or fad dieting, intensive exercise). Obesity is influenced by genetics, environment, behaviour and socioeconomic conditions. ${ }^{13}$ Recent research also suggests that geography and income impact obesity and physical activity levels. ${ }^{14-16}$ In particular, rural citizens tend to have higher levels of obesity than their urban counterparts. ${ }^{16} 17$ This same trend is true for income, such that people with lower incomes present with higher obesity levels than those with higher income levels. ${ }^{14}$ In Canada, on average, rural citizens have lower incomes $^{18} 19$ and high obesity rates related to physical inactivity. ${ }^{15}$ 
Despite its complex aetiology, obesity can be treated. The most common treatment involves lifestyle changes such as improved nutrition and increased physical activity. ${ }^{20-23}$ Studies have demonstrated that, for example, cardiometabolic risk factors were reduced in a group of morbidly obese individuals after a 1 year lifestyle intervention targeting nutrition and physical activity. ${ }^{24}$ In another study examining the effectiveness of an 18-month intervention focusing on exercise and goal setting, a group of sedentary, middle-aged women increased their participation in physical activity and improved their self-efficacy related to overcoming barriers and accomplishing goals. ${ }^{25}$ An analysis of the literature examining intervention programmes for overweight and obese people concluded that intervention programmes "...have potential in changing energy balance related lifestyle and anthropometric outcomes." 26

Research indicates that lifestyle intervention programmes can work ${ }^{27}$ if the participants remain engaged long enough to complete the programming. It seems that psychological support as part of lifestyle intervention programmes is important to assist in weight management. ${ }^{28}{ }^{29}$ Research examining the effectiveness of lifestyle changing studies that included goal setting sessions, or sometimes also called group-mediated cognitivebehavior interventions (GMCBI), ${ }^{30}$ had better outcomes compared with those without GMCBI components. ${ }^{31-34}$

Although primary care providers can prescribe lifestyle changes, such treatments have poor uptake. ${ }^{35} 36$ Obese patients need guidance to learn and implement lifestyle changes. Primary care providers are often unable to provide this kind of complex, prolonged and intense treatment, ${ }^{37} 38$ whereas other professionals are uniquely trained for it. A Canadian Society for Exercise Physiology (CSEP) Certified Exercise Physiologist (CSEP-CEP) is certified to assess exercise capacity and prescribe appropriate physical activity and rehabilitative exercise programming to individuals with a variety of clinical conditions. Certification is achieved after completing a 4-year Bachelor's degree in exercise sciences from an accredited postsecondary institution specialising in health-related and performance-related fitness applications, clinical experiences with various populations, and successful completion of the Society's written and practical examinations. CSEP Certified Personal Trainers (CSEP-CPT) have a minimum of 2 years of university/ college coursework in a specific core competency related to exercise and have successfully completed standard theory and practical examinations. The CSEP certifications are comparable to those provided in the USA by the American College of Sports Medicine. Registered Dietitians (RDs) must successfully complete a Bachelor's degree in food and nutrition from an accredited university, a 12-month supervised internship and a written national accreditation examination with Dietitians of Canada. These non-physician allied health professionals are uniquely trained to treat obesity and are excellent candidates to deliver lifestyle intervention programmes.
The primary objective of the current study was to examine how well a 6-month active intervention (based on physical activity and teaching nutritional knowledge) with content specialists, followed by a 6 -month self-management period, would improve the health of obese participants. In addition, we tested the hypothesis that behavioural change strategies guided by principles of GMCBI would further improve health outcomes. Lastly, we examined whether the geographic location of the intervention (urban/rural) was related to the effectiveness of the health outcomes. We deliberately did not include a control group in this long and complex study. The literature indicates that when obese people do not engage in lifestyle modifications, they will not improve their health outcomes. ${ }^{39-41}$ Hence, we felt that inclusion of a control group that received no intervention would provide little new information.

\section{METHODS}

\section{Setting and study population}

The Healthy Eating, Active Living for Tomorrow's Health (HEALTH) study was conducted in the Eastern Canadian Province of New Brunswick. This province has one of the highest obesity rates in the country. ${ }^{42}$ The multisite study was conducted in three separate locations, two rural and one urban, using four separate groups, two rural and two urban (the two urban groups were conducted in the same city). Owing to the long, cold and icy winters, the intervention took place indoors. The urban interventions took place in two public arenas equipped with a community room and a walking track. One of the two rural interventions took place in a local arena that did not have a walking track. The participants walked the perimeter of the rink and through the stands. The other rural community did not have an arena, so the programme was delivered in the local Legion Hall. Tables were used to create walking lanes.

Recruitment was achieved through media articles and advertisements in physicians' offices and no incentives to patients or their physicians were provided. Potential participants were screened to assess if they fit the inclusion criteria: having a BMI between 30 and $40 \mathrm{~kg} / \mathrm{m}^{2}$ and being between 19 and 69 years of age. To ensure that participants were physically able to complete the intervention, each participant obtained approval to participate from their physician by having their physician complete a Physical Activity Readiness Medical Examination (PARmed-X). Once deemed suitable by their physician, participants were able to enrol in the study. A total of 146 participants were enrolled in the study, of whom $85 \%$ were female. Participants were enrolled into one of two urban or two rural community groups based on their community of residence. All four experimental groups received InI and Urban I and Rural II received InI and InII. The Urban I and Rural I groups began their programmes in January 2012 while the Urban II and Rural II groups started in September 
2012. Intervention programme staff travelled to the communities to deliver the programme.

A priori sample size calculations indicated that a minimum of 25 participants were required for each group; we oversampled and allowed 35 participants in each group. ${ }^{\mathrm{i}}$ After recruitment, participants were required to sign a consent form in order to participate in the study.

\section{Intervention}

The active intervention (InI) consisted of $1 \mathrm{~h}$ of physical activity three times a week over a 6 -month period. The physical activity was supervised and delivered by a CSEPCEP and CSEP-CPTs, as well as CSEP-CEP and CSEPCPT students in training. Additionally, all participants took part in biweekly nutritional interventions delivered by an RD. The nutritional component was comprehensive, covering topics including learning how to read nutrition food labels; portion control; fat, sugar and sodium intake; meal planning; and grocery shopping, including a grocery store tour. Nested in the InI was a second intervention, InII, in which two of the four groups (one urban, one rural) received biweekly GMCBI sessions delivered by an exercise psychologist. $^{30} 43$ The assignment of the groups for GMCBI was in advance and based on the location of the intervention, and not based on the individual participants' characteristics.

The GMCBI sessions were developed to equip participants with psychological skills to help address the barriers participants often perceive or create when attempting to make lifestyle changes, particularly around physical activity. The sessions provided participants with psychological skills to address these challenges while also leveraging the positive aspects of group dynamics to motivate and support new behaviours around nutrition and physical activity. The GMCBI sessions addressed group identity, teaching self-monitoring skills, individual and group goal-setting, developing strategies to overcoming barriers, sharing and support of group and individual goals, relapse prevention planning, cognitive regulation strategies, and transitory strategies for when the programme terminated. ${ }^{30} 4445$

Each InI was followed by a 6-month self-management period. Each participant received a lifestyle resource book, but there was no contact between programme staff and participants for the duration of this phase. For the entire intervention, no control groups were used. Past

\footnotetext{
${ }^{\mathrm{i}}$ In order to ensure a sufficient sample to alleviate the possibility of rejecting a false null hypothesis, a power calculation was performed based on exercise data from a previous study. In that study participants improved their walk time for a $1.6 \mathrm{~km}$ distance between (T1 mean 15.3 SD 1.8; T2 14.1 SD1.5). Assuming an $\alpha$ level of $\mathrm{p}=0.05$ and a desired power level of $\beta=0.80$ and the need to compare two groups, calculations indicate 23 participants were required in each group $(4 \times 23=92)$. Owing to a $32 \%$ attrition rate in the 8 -week study we felt it would be prudent to over-recruit the number of participants to 35 in each of the four groups.
}

research robustly indicates that when obese people do not engage in lifestyle changes, their health outcomes typically do not improve. ${ }^{39-41}$

\section{Instruments and assessment}

Health measures such as blood pressure, resting heart rate, weight and height (BMI), waist circumference and mental health-part of the SF-36v2 Health Survey-were measured. We focused on the SF-36v2 Mental Health Summary Score because 26 participants scored at or below 42, which is the cut-off point for a positive first stage depression screening.

Additional measures related to physiological abilities, nutrition knowledge and behaviour were taken but will not be reported in this paper. We hypothesised that the intervention programme and the GMCBI would improve the health and well-being of the participants but geographic location (rural and urban) would have little impact on outcomes. Participants were measured at three different times: preintervention (T0) for initial measurements, after the 6-month active intervention (T1) and after the 6-month self-management phase (T2) for their final measurements. The measurements were conducted by the CPTs under the leadership of one CEP. The staff was the same throughout the entire programme, for all four sites, including all three measurement periods.

\section{Statistical methods}

For the primary objective of this study, the effectiveness of both components of the intervention (InI and the self-management period) was examined by conducting a repeated measures multivariate analysis of variance (MANOVA) with time of measurement (T0, T1, and T2) as the independent variable and five dependent variables (resting heart rate, systolic blood pressure, waist circumference, BMI and the mental health component summary). This analysis was conducted using only the final 59 participants who completed all three measurement points.

Differences in the improvement of the health outcomes between the GMCBI and non-GMCBI groups were examined using a between-subject MANOVA. Difference scores were calculated between $\mathrm{T} 0$ and $\mathrm{T} 1$, $\mathrm{T} 0$ and $\mathrm{T} 2$, and $\mathrm{T} 1$ and $\mathrm{T} 2$ for resting heart rate, systolic blood pressure, waist circumference, BMI and the mental health component summary on the SF-36v2. These difference scores were then included as the dependent variables in the GMCBI MANOVA with GMCBI status as the independent variable. The comparison of the effectiveness of the intervention between geographic locations (urban/rural) was also examined using a between-subject MANOVA, with the health variables difference scores included as the dependent variables and geographic location (urban/rural) as the independent variable. 


\section{RESULTS}

\section{Participant profile}

Over the four sites, a total of 146 participants enrolled in the study ( $85 \%$ women and $15 \%$ men). All participants were between the ages of 20 and 69 years, with a mean age of 50.47 ( $\mathrm{SD}=11.03)$. Most were self-referred, with a few referred by their physician $(\mathrm{N}=7)$. See table 1 for additional descriptive data.

Participants' health measures at intake (T0) are listed in table 2. The mean level of obesity among participants was class II $\left(36.5 \mathrm{~kg} / \mathrm{m}^{2}\right.$; SD 3.09$)$, and systolic and diastolic blood pressures were elevated.

\section{Attendance and attrition}

On average, participants attended $67 \%$ of the $\mathrm{InI}$ sessions; however, attrition rates were high. After InI (T0), 57 participants $(39 \%)$ had terminated the programme and a further $30(20.5 \%)$ participants were lost for the T2 measurements, for a total dropout of 87 participants (59.5\%). Attrition rates did not differ between urban and rural sites.

\section{Effectiveness of InI (physical activity)}

Results from the repeated measures MANOVA for the aggregate data of all four groups revealed that there was a significant main effect of time, indicating that the difference in the five health outcomes across the three measurement points was significant, $\mathrm{F}(2,116)=19.57$, $\mathrm{p}<0.001$ (see table 3). To follow-up the significant main effect, Bonferroni post-hoc tests were conducted for each dependent variable independently. These post-hoc tests revealed that all five health outcomes differed significantly from $\mathrm{T} 0$ to $\mathrm{T} 1$ and from $\mathrm{T} 0$ to $\mathrm{T} 2$, but not from T1 to T2 (see table 4). This indicates that the participants improved on all five health outcomes during the InI and maintained their health status during the selfmanagement phase. The interaction effects between the measurement points and the health outcomes were not significant $(p>0.05)$, indicating that the improvement in health outcomes did differ significantly across the health outcomes. For the SF-36v2, we focused on the Mental Health Summary Score because 26 participants scored

Table 1 Participant demographic profile $(\mathrm{N}=146)$

\begin{tabular}{|c|c|c|c|c|c|}
\hline Characteristics & $\begin{array}{l}\text { Total } \\
\text { N (\%) }\end{array}$ & $\begin{array}{l}\text { Urban I } \\
\text { GMCBI } \\
\text { N (\%) }\end{array}$ & $\begin{array}{l}\text { Rural I } \\
\text { N (\%) }\end{array}$ & $\begin{array}{l}\text { Urban II } \\
\text { N (\%) }\end{array}$ & $\begin{array}{l}\text { Rural II } \\
\text { GMCBI } \\
\text { N (\%) }\end{array}$ \\
\hline Male & $22(15)$ & $7(16)$ & $4(11)$ & $7(20)$ & $4(12)$ \\
\hline Female & $124(85)$ & $36(84)$ & 31 (89) & $28(80)$ & $29(88)$ \\
\hline Urban & $78(53)$ & 100 & 0 & 100 & 0 \\
\hline Rural & $68(47)$ & 0 & 100 & 0 & 100 \\
\hline Overweight $\left(25.0-29.9 \mathrm{~kg} / \mathrm{m}^{2}\right)$ & $02(01)$ & 0 & 03 & 03 & 0 \\
\hline Class I $\left(30.0-34.9 \mathrm{~kg} / \mathrm{m}^{2}\right)$ & $43(30)$ & 26 & 26 & 43 & 24 \\
\hline Class II $\left(35.0-39.9 \mathrm{~kg} / \mathrm{m}^{2}\right)$ & $82(56)$ & 51 & 68 & 40 & 67 \\
\hline Class III $\left(\geq 40.0 \mathrm{~kg} / \mathrm{m}^{2}\right)^{\star}$ & 19 (13) & 23 & 03 & 14 & 09 \\
\hline Single/separated/divorced/widowed & $37(25)$ & 26 & 20 & 37 & 18 \\
\hline Married/common law/engaged & $109(75)$ & 74 & 80 & 63 & 82 \\
\hline \multicolumn{6}{|l|}{ Education } \\
\hline High school or less & $44(30)$ & 9 & 43 & 29 & 45 \\
\hline Postsecondary & $79(54)$ & 70 & 49 & 43 & 52 \\
\hline Graduate degree & $23(16)$ & 21 & 8 & 28 & 3 \\
\hline Working full-time & $84(58)$ & 61 & 57 & 62 & 52 \\
\hline Working part time & $24(17)$ & 16 & 11 & 17 & 21 \\
\hline Not working (retired/unemployed/on leave) & $37(26)$ & 23 & 32 & 21 & 27 \\
\hline Family income: & $50(36)$ & 20 & 40 & 40 & 52 \\
\hline \multicolumn{6}{|l|}{$<\$ 40000 \dagger$} \\
\hline Family income: between $\$ 40001$ and $\$ 80000$ & $49(36)$ & 44 & 40 & 24 & 33 \\
\hline Family income: >\$80 001 & $38(28)$ & 36 & 20 & 36 & 15 \\
\hline \multicolumn{6}{|l|}{ Diagnosed with: } \\
\hline Type II diabetes & $17(12)$ & 12 & 9 & 14 & 12 \\
\hline Hypertension & $58(40)$ & 35 & 51 & 37 & 36 \\
\hline High cholesterol & $41(28)$ & 23 & 34 & 29 & 27 \\
\hline Vascular diseases & $15(10)$ & 07 & 09 & 11 & 15 \\
\hline Lung diseases & $24(16)$ & 05 & 17 & 26 & 21 \\
\hline Musculoskeletal diseases & $43(30)$ & 26 & 31 & 34 & 27 \\
\hline Current smoker & $12(08)$ & 02 & 09 & 09 & 15 \\
\hline Positive for depression & $40(27)$ & 40 & 20 & 31 & 15 \\
\hline
\end{tabular}


Table 2 Participant health characteristics $(\mathrm{N}=146)$

\begin{tabular}{lcrr}
\hline Characteristics & Urban I and II M (SD) & Rural I and II M (SD) & Total \\
\hline M (SD)
\end{tabular}

at or below 42, which is the cut point for a positive first stage depression screening.

\section{Effectiveness of Inll (GMCBI sessions)}

The urban and rural groups receiving InII (GMCBI) had significantly lower attrition rates as compared with the non-GMCBI groups during the active interventions $(29 \%$ vs $50 \%)$ and the self-management phase $(31 \%$ vs $37 \%)$. The difference in attrition rates between the two groups for both the active intervention and the self-management phase was significant $\chi^{2}(2)=7.08, \quad \mathrm{p}<0.05$. However, the overall attendance in terms of the number of InI sessions attended groups were not significantly different $(72 \%$ vs $62 \%), \mathrm{F}(1,86)=2.17$, $\mathrm{p}>0.05$.

The two groups (1 urban and 1 rural) that received GMCBI sessions were similar to the two non-GMCBI groups with regard to their health profile. Both were class II obese ( $37 \mathrm{vs} 35.9 \mathrm{~kg} / \mathrm{m}^{2}$ ) and the mean age was identical, as was the ratio of females/males. However, the GMCBI group had more urban participants $(57 \%$ vs $43 \%)$ and slightly lower levels of self-reported diagnosed hypertension $(36 \%$ vs $44 \%$ ), hyperlipidaemia ( $25 \%$ vs $31 \%)$, lung disease $(12 \%$ vs $21 \%)$ and musculoskeletal disease $(26 \%$ vs. $33 \%)$, according to self-reports. However, none of these differences were statistically significant, $\mathrm{p}>0.05$.

Results from the between-subject GMCBI MANOVA revealed that only the change in waist circumference differed significantly between the groups. The change in waist circumference from $\mathrm{T} 0$ to $\mathrm{T} 1 \quad(\mathrm{~F}(1,57)=5.95$, $\mathrm{p}<0.05)$ and the change between $\mathrm{T} 1$ and $\mathrm{T} 2(\mathrm{~F}(1,57)$ $=5.69, \mathrm{p}<0.05)$ were significantly different between GMCBI and non-GMCBI groups (see table 5 for means across groups). Waist circumference decreased modestly in those receiving GMCBI during the active and selfmanagement phases of the intervention while in the non-GMBI group there was a large decrease in waist circumference during the active phase with an increase in waist circumference observed during self-management.

\section{Differences between urban and rural groups}

The examination of the descriptive statistics suggested that the urban and rural groups differed on several variables. In particular, there were more urban participants $(\mathrm{N}=78)$ as compared with rural participants $(\mathrm{N}=68)$, and the rural participants were older $(\mathrm{M}=51.85, \mathrm{SD}=9.69)$ than the urban participants $(\mathrm{M}=49.26, \mathrm{SD}=12.01)$. However, these differences ( $\mathrm{N}$ and age) were not statistically significant $(\mathrm{p}>0.05)$. The urban and rural groups differed in terms of level of education and annual household income. Urban participants reported a higher yearly family income $(\mathrm{M}=6.09, \mathrm{SD}=3.10)$ as compared with rural participants $(\mathrm{M}=4.59, \mathrm{SD}=2.70)$, $\mathrm{F}(1,137)=9.06, \mathrm{p}<0.01$; and urban participants received higher levels of education $(\mathrm{M}=3.63, \mathrm{SD}=0.11)$ as compared with rural participants $(\mathrm{M}=2.68, \mathrm{SD}=0.12)$, $F(1,144)=35.07, p<0.001$. There were no statistical differences with regard to self-reported diagnosis of hypertension, hyperlipidaemia and lung disease.

Results from the between-subject rural and urban locations MANOVA revealed that only the change in the mental health component summary of the SF-36v2 differed significantly between urban and rural groups, $\mathrm{F}(1, \quad 57)=5.35, \quad \mathrm{p}<0.05$, with urban participants $(\mathrm{M}=-1.4325, \mathrm{SD}=5.89)$ reporting lower scores on the SF36v2 than rural participants $(\mathrm{M}=1.9230, \mathrm{SD}=5.12)$.

Table 3 Health outcomes using group means between T0, T1 and T2 ( $N=59)$

\begin{tabular}{lcrr} 
& T0 & T1 & T2 \\
Health outcomes & M (SD) & M (SD) & M (SD) \\
\hline Resting heart rate $(\mathrm{bpm})$ & $81.49(10.61)$ & $76.41(10.20)$ & $76.39(11.22)$ \\
Systolic blood pressure $(\mathrm{mm} \mathrm{Hg})$ & $141.36(15.22)$ & $134.85(13.46)$ & $132.47(13.31)$ \\
Body mass index $\left(\mathrm{kg} / \mathrm{m}^{2}\right)$ & $36.11(3.12)$ & $35.15(3.38)$ & $35.14(3.84)$ \\
Waist circumference $(\mathrm{cm})$ & $115.11(9.04)$ & $110.92(10.56)$ & $110.30(10.77)$ \\
SF-36v2 Mental health summary & 46 & $52.63(14.08)$ & $52.73(14.85)$ \\
\hline
\end{tabular}


Table 4 Bonferroni post-hoc results for all health outcomes across T0, T1 and T2 ( $\mathrm{N}=59)$

\begin{tabular}{|c|c|c|c|c|}
\hline Health outcomes & M (SD) & $\begin{array}{l}\text { T0-T1 } \\
\text { p value }\end{array}$ & $\begin{array}{l}\text { T0-T2 } \\
\mathrm{p} \text { value }\end{array}$ & $\begin{array}{l}\mathrm{T} 1-\mathrm{T} 2 \\
\mathrm{p} \text { value }\end{array}$ \\
\hline Resting heart rate (bpm) & & 0.001 & 0.006 & 1.00 \\
\hline TO & $81.49(10.61)$ & & & \\
\hline T1 & $76.41(10.20)$ & & & \\
\hline T2 & 76.39 (11.22) & & & \\
\hline Systolic blood pressure $(\mathrm{mm} \mathrm{Hg})$ & & 0.001 & $<0.001$ & 0.627 \\
\hline TO & $141.36(15.22)$ & & & \\
\hline T1 & $134.85(13.46)$ & & & \\
\hline $\mathrm{T} 2$ & $132.47(13.31)$ & & & \\
\hline Body mass index $\left(\mathrm{kg} / \mathrm{m}^{2}\right)$ & & $<0.001$ & 0.004 & 1.00 \\
\hline To & $36.11(3.12)$ & & & \\
\hline T1 & 35.15 (3.38) & & & \\
\hline T2 & $35.14(3.84)$ & & & \\
\hline Waist circumference $(\mathrm{cm})$ & & $<0.001$ & $<0.001$ & 1.00 \\
\hline TO & $115.11(9.04)$ & & & \\
\hline T1 & $110.92(10.56)$ & & & \\
\hline T2 & $110.30(10.77)$ & & & \\
\hline SF-36v2 Mental health summary & & 0.01 & 0.01 & 1.00 \\
\hline TO & $49.21(11.31)$ & & & \\
\hline T1 & $52.63(8.60)$ & & & \\
\hline T2 & $52.73(9.05)$ & & & \\
\hline
\end{tabular}

Moreover, post-hoc comparisons revealed that the difference in mental health scores between the urban and rural groups were only significant between $\mathrm{T} 1$ and $\mathrm{T} 2$, suggesting that rural participants were able to maintain

\begin{tabular}{|c|c|c|c|c|}
\hline \multirow{2}{*}{$\begin{array}{l}\text { Change in health } \\
\text { outcomes }\end{array}$} & \multicolumn{2}{|c|}{$\begin{array}{l}\text { GMCBI } \\
\text { group }\end{array}$} & \multicolumn{2}{|c|}{$\begin{array}{l}\text { Non-GMCBI } \\
\text { group }\end{array}$} \\
\hline & Mean & SD & Mean & SD \\
\hline \multicolumn{5}{|c|}{ Resting heart rate (bpm) } \\
\hline D1 & -4.97 & 10.38 & -5.27 & 10.36 \\
\hline D2 & -3.59 & 11.02 & -7.64 & 13.85 \\
\hline D3 & 1.38 & 11.38 & -2.36 & 10.81 \\
\hline \multicolumn{5}{|c|}{ Systolic blood pressure $(\mathrm{mm} \mathrm{Hg})$} \\
\hline D1 & -7.62 & 13.64 & -4.64 & 11.49 \\
\hline D2 & -9.35 & 17.71 & -8.09 & 15.51 \\
\hline D3 & -1.73 & 13.83 & -3.45 & 15.44 \\
\hline \multicolumn{5}{|c|}{ Body mass index $\left(\mathrm{kg} / \mathrm{m}^{2}\right)$} \\
\hline D1 & -0.93 & 1.38 & -1.02 & 1.78 \\
\hline D2 & -1.00 & 2.50 & -0.92 & 1.67 \\
\hline D3 & -0.07 & 2.11 & 0.10 & 0.94 \\
\hline \multicolumn{5}{|c|}{ Waist circumference $(\mathrm{cm})$} \\
\hline $\mathrm{D} 1^{*}$ & -2.45 & 6.76 & -7.10 & 7.60 \\
\hline D2 & -5.16 & 9.64 & -4.22 & 5.07 \\
\hline $\mathrm{D}^{*}$ & -2.71 & 8.61 & 2.88 & 8.86 \\
\hline \multicolumn{5}{|c|}{ Mental health component summary } \\
\hline D1 & 3.60 & 9.67 & 3.12 & 7.21 \\
\hline D2 & 3.68 & 9.37 & 3.27 & 8.52 \\
\hline D3 & 0.08 & 6.56 & 0.15 & 4.22 \\
\hline
\end{tabular}

$\mathrm{D} 1=\mathrm{T} 1-\mathrm{T} 0, \mathrm{D} 2=\mathrm{T} 2-\mathrm{TO} ; \mathrm{D} 3=\mathrm{T} 2-\mathrm{T} 1$.

${ }^{*} \mathrm{p}<0.05$.

Negative values represent a reduction. their mental health better during the self-management phase than their urban counterparts (see table 6).

\section{DISCUSSION}

Weight loss is a significant challenge, particularly for older adults. ${ }^{47}$ Although many participants were still obese at the end of the intervention, they possessed a much healthier obese phenotype in that several important health measures improved for the target population as a result of the current intervention. The dropout rate, or therapy incompliance, was high but consistent with other similar programmes. ${ }^{48}{ }^{49}$ In fact, research suggests a lack of compliance with even less demanding therapies, such as taking oral medications for hypertension. ${ }^{50}$ Poor compliance with medical therapy is considered common, and may significantly impact outcomes of chronic disease issues requiring serious attention. ${ }^{51}$

On the basis of our study results, it is evident that the GMCBI sessions are an important component of any lifestyle therapy as participants adhered to the intervention longer than did those who did not receive GMCBI. While both groups most likely experienced many of the same challenges, the GMCBI sessions dealt directly with these challenges and helped people persevere. By discussing challenges directly, participants may have indirectly eliminated the bank of acceptable rationalisations for their non-participation. ${ }^{29}$ In addition, the GMCBI groups were also able to maintain their reduced waist circumference better than the non-GMCBI group during the self-management period.

Nevertheless, to make a programme like this sustainable in the community, dropout is a serious concern. Although all participants appeared motivated, many 
Table 6 Means and SDs for the health outcomes difference scores between urban and rural groups $(\mathrm{N}=59)$

\begin{tabular}{|c|c|c|c|c|}
\hline \multirow{2}{*}{$\begin{array}{l}\text { Change in health } \\
\text { outcomes }\end{array}$} & \multicolumn{2}{|c|}{ Urban group } & \multicolumn{2}{|c|}{ Rural group } \\
\hline & Mean & SD & Mean & SD \\
\hline \multicolumn{5}{|c|}{ Resting heart rate (bpm) } \\
\hline D1 & -5.13 & 10.91 & -5.04 & 9.71 \\
\hline D2 & -2.53 & 12.96 & -8.15 & 10.67 \\
\hline D3 & 2.60 & 11.22 & -3.11 & 10.60 \\
\hline \multicolumn{5}{|c|}{ Systolic blood pressure $(\mathrm{mm} \mathrm{Hg})$} \\
\hline D1 & -4.88 & 14.27 & -8.44 & 10.87 \\
\hline D2 & -6.56 & 16.17 & -11.63 & 17.41 \\
\hline D3 & -1.69 & 12.12 & -3.19 & 16.81 \\
\hline \multicolumn{5}{|c|}{ Body mass index $\left(\mathrm{kg} / \mathrm{m}^{2}\right)$} \\
\hline D1 & -1.11 & 1.35 & -0.78 & 1.72 \\
\hline D2 & -0.84 & 1.83 & -1.12 & 2.61 \\
\hline D3 & 0.27 & 1.45 & -0.34 & 2.04 \\
\hline \multicolumn{5}{|c|}{ Waist circumference $(\mathrm{cm})$} \\
\hline D1 & -4.14 & 7.90 & -4.24 & 6.85 \\
\hline D2 & -6.29 & 7.79 & -3.06 & 8.47 \\
\hline D3 & -2.15 & 11.31 & 3.06 & 8.47 \\
\hline \multicolumn{5}{|c|}{ Mental health component summary } \\
\hline D1 & 3.85 & 7.27 & 2.92 & 10.39 \\
\hline D2 & 2.41 & 7.65 & 4.85 & 10.36 \\
\hline D3 $^{*}$ & -1.43 & 5.89 & 1.92 & 5.12 \\
\hline
\end{tabular}

were not yet ready to commit to making lifestyle changes. However, among those who completed the intervention, the sense of camaraderie and support that developed was important in their continuation on the path of lifestyle changes. This is consistent with the teaching of GMCBI. ${ }^{52}$ Community programmes may need to accept that participants may need to join lifestyle change programmes several times before they successfully complete staying in a programme, akin to what often happens in smoking cessation programmes. ${ }^{53}$

In general, the question of whether participants resided in rural or urban communities did not have an impact on the health outcomes, with the exception that rural participants scored more favourably on the mental health component summary of the SF-36v2. This is somewhat surprising considering that the rural participants had lower incomes and less education. Although income and education may impact health, the sample size was too small to examine the socioeconomic background and its impact on outcomes. Interestingly, there was no difference in BMI between the urban and rural groups before, during and after the intervention as is often reported, even though the rural participants had less education and lower incomes. They had slightly higher levels of self-reported diagnosed chronic disease, and a greater incidence of smoking, but lower levels of scoring positive for depression on the SF-36v2. Therefore, this study has demonstrated that rural participants should be offered lifestyle change programmes as often as urban participants, despite the fact that many rural communities lack 'proper' exercise facilities. ${ }^{54}$ In fact, this study shows that significant health improvements can be made using existing community space such as a meeting hall or community centre and little equipment so long as knowledgeable exercise and nutritional staff are available to implement and lead the programme. During the self-management phase, participants did not make additional gains and some trended towards their preintervention state, suggesting that even after 6 months of intensive regular contact with programme staff the participants had not fully adopted new lifestyle behaviours. This is consistent with other studies and suggests that obese adults may benefit from programming that continues contact in some form for an extended period. ${ }^{55}$

\section{The challenges of community-based programming/ limitations}

This intervention was conducted in a real-world environment and sought to strike a balance between scientific control and allowing the intervention to unfold as it would in any community circumstance. Every attempt was made to ensure that the intervention was consistent between the four sites despite physical differences in facilities (walking track vs no walking track). The realities of conducting an intensive prolonged community-based intervention include but are not limited to cancelling sessions due to snowstorms, bad roads and changing seasonal weather. Although these issues are difficult to quantify, they play a significant role in delivering an intervention in a community setting. The January and September start date of the intervention for the groups may have had an impact on the attrition, although both periods covered a substantial part of the winter months, traditionally a time in New Brunswick when people reduce outdoor activities. Initially, we wanted to focus on class I and II obese people for health and safety reasons; however, in the end, we did include $13 \%$ of participants who had a slightly higher BMI than $40 \mathrm{~kg} / \mathrm{m}^{2}$ because of the numbers we needed to have enrolled in each site.

This study relied on self-referred or physician-referred participants, with the majority of participants being female and having a BMI between 30 and $42 \mathrm{~kg} / \mathrm{m}^{2}$, thus introducing selection bias. The intervention used premeasure and postmeasure and did not use a control group. The potential lack of experimental control was at least partially overcome by using experienced, welltrained staff and objective measures that can be reliably obtained under differing field conditions. Despite these limitations, this study embodies the direct translation of laboratory and clinical-based best practices for treating obesity through increased physical activity, nutritional education and counselling and allows for evaluation of their efficacy in a real-world setting.

\section{Future directions}

We learnt that a 6-month intervention is not long enough. Considering that, on average, participants were 
able to attend three quarters of the sessions, it seems that a longer intervention would be more beneficial. More work needs to be conducted to ensure adherence to lifestyle interventions for people who are already motivated to make changes, to reduce dropout.

\section{CONCLUSION}

Primary healthcare providers should use other trained certified professionals to assist in the treatment of obesity in utilising non-pharmaceutical lifestyle changes in their own communities. Simple physical activity group programmes led by CSEP-CEPs or CSEP-CPTs and nutritional group education programmes led by RDs should become an extended part of the primary healthcare community. GMCBI appears to be particularly effective in helping obese patients achieve success in overcoming the barriers that lie between them and their participation in healthy lifestyle activities. Programmes need to be designed in such a way as to allow obese patients to make several attempts at making lifestyle changes.

\section{Author affiliations \\ ${ }^{1}$ Dalhousie University Family Medicine Teaching Unit, Dr. Everett Chalmers Regional Hospital, Fredericton, Canada \\ 2Department of Sport \& Exercise Science, University of Auckland, Auckland, New Zealand \\ ${ }^{3}$ Psychology Department, University of New Brunswick, Fredericton, New Brunswick, Canada}

Contributors BM and SAR were the principal investigators on the grants and they have played a significant role in all aspects of the project, including data analysis and writing of the manuscript. RAH has participated in the project as the GMCBI teacher and played an important role in the analysis of the data and the writing of the manuscript. KSM was the project coordinator and assisted in collecting and analysing the data as well as in the writing of the manuscript. AET assisted in the analysis of the data and the writing of the manuscript.

Funding This research was supported by the Canadian Institutes for Health Research grant MOP 10940 and the New Brunswick Health Research Foundation.

\section{Competing interests None.}

Patient consent Obtained.

Ethics approval The study was reviewed by the University of New Brunswick research ethics board \#2011-105 and by the Horizon Health Network research ethics board \#2011-1629.

Provenance and peer review Not commissioned; externally peer reviewed.

Data sharing statement All the data of the study are housed in the Family Medicine Teaching Unit (FMTU) and the University of Auckland. Only team members have access to the raw data for the sole purpose of dissemination of the results. The grant team members can work at the FMTU offices to access and analyse the data. Data analysis is ongoing.

Open Access This is an Open Access article distributed in accordance with the Creative Commons Attribution Non Commercial (CC BY-NC 4.0) license, which permits others to distribute, remix, adapt, build upon this work noncommercially, and license their derivative works on different terms, provided the original work is properly cited and the use is non-commercial. See: http:// creativecommons.org/licenses/by-nc/4.0/

\section{REFERENCES}

1. American Heart Association. Physical activity in older Americans. Secondary physical activity in older Americans, 2013. http://www. heart.org/HEARTORG/GettingHealthy/PhysicalActivity/ FitnessBasics/Physical-Activity-in-Older-Americans_UCM_308039_ Article.jsp

2. Sjosten N, Kivimaki M, Singh-Manoux A, et al. Change in physical activity and weight in relation to retirement: the French GAZEL Cohort Study. BMJ Open 2012;2:e000522.

3. Twells LK, Gregory DM, Reddigan J, et al. Current and predicted prevalence of obesity in Canada: a trend analysis. CMAJ Open 2014;2:E18-26.

4. World Health Organization. Fact sheet: obesity and overweight. Secondary fact sheet: obesity and overweight. 2009.

5. Katzmarzyk PT, Mason C. Prevalence of class I, II and III obesity in Canada. CMAJ 2006;174:156-7.

6. Statistics Canada. Canadian Community Health Survey Ottawa, 2010.

7. Gordon-Larsen $\mathrm{P}$, Griffiths $\mathrm{P}$, Bentley ME, et al. Barriers to physical activity: qualitative data on caregiver-daughter perceptions and practices. Am J Prev Med 2004;27:218-23.

8. Nugent RA, Fathima SF, Feigl AB, et al. The burden of chronic kidney disease on developing nations: a 21st century challenge in global health. Nephron Clin Pract 2011;118:c269-77.

9. Himes CL, Reynolds SL. Effect of obesity on falls, injury, and disability. J Am Geriatr Soc 2012;60:124-9.

10. Greenberg JA. The obesity paradox in the US population. Am J Clin Nutr 2013;97:1195-200.

11. Steensma $\mathrm{C}$, Loukine L, Orpana $\mathrm{H}$, et al. Comparing life expectancy and health-adjusted life expectancy by body mass index category in adult Canadians: a descriptive study. Popul Health Metrics 2013;11:21.

12. King WC, Kalarchian MA, Steffen KJ, et al. Associations between physical activity and mental health among bariatric surgical candidates. J Psychosom Res 2013;74:161-9.

13. Rosin O. The economic causes of obesity: a survey. J Econ Surv 2008;22:617-47.

14. Hajizadeh M, Campbell MK, Sarma S. Socioeconomic inequalities in adult obesity risk in Canada: trends and decomposition analyses. Eur J Health Econ 2014;15:203-21.

15. Parks SE, Housemann RA, Brownson RC. Differential correlates of physical activity in urban and rural adults of various socioeconomic backgrounds in the United States. J Epidemiol Community Health 2003:57:29-35.

16. Bruner MW, Lawson J, Pickett W, et al. Rural Canadian adolescents are more likely to be obese compared with urban adolescents. Int $J$ Pediatr Obes 2008;3:205-11.

17. Reeder BA, Chen Y, Macdonald SM, et al. Regional and rural-urban differences in obesity in Canada. Canadian Heart Health Surveys Research Group. CMAJ 1997;157(Suppl 1):S10-16.

18. Plotnikoff RC, Mayhew A, Birkett N, et al. Age, gender, and urbanrural differences in the correlates of physical activity. Prev Med 2004;39:1115-25.

19. Befort CA, Nazir N, Perri MG. Prevalence of obesity among adults from rural and urban areas of the United States: findings from NHANES (2005-2008). J Rural Health 2012;28:392-7.

20. Noakes M, Foster PR, Keogh JB, et al. Meal replacements are as effective as structured weight-loss diets for treating obesity in adults with features of metabolic syndrome. J Nutr 2004;134:1894-9.

21. Cooney GM, Dawn K, Greig CA, et al. Exercise and depression. September 12 edn: The Cochrane Library, 2013.

22. Earnest CP, Johannsen NM, Swift DL, et al. Dose effect of cardiorespiratory exercise on metabolic syndrome in postmenopausal women. Am J Cardiol 2013;111:1805-11.

23. Hill JO, Wyatt HR. Role of physical activity in preventing and treating obesity. J Appl Physiol 2005;99:765-70.

24. Goodpaster BH, Delany JP, Otto AD, et al. Effects of diet and physical activity interventions on weight loss and cardiometabolic risk factors in severely obese adults: a randomized trial. JAMA 2010;304:1795-802.

25. Cox KL, Gorely TJ, Puddey IB, et al. Exercise behaviour change in 40 to 65-year-old women: The SWEAT Study (Sedentary Women Exercise Adherence Trial). Br J Health Psychol 2003;8(Pt 4): 477-95.

26. Kremers S, Reubsaet A, Martens M, et al. Systematic prevention of overweight and obesity in adults: a qualitative and quantitative literature analysis. Obes Rev 2010;11:371-9.

27. Kujala UM, Jokelainen J, Oksa $\mathrm{H}$, et al. Increase in physical activity and cardiometabolic risk profile change during lifestyle intervention in primary healthcare: 1 -year follow-up study among individuals at high risk for type 2 diabetes. BMJ Open 2011;1:e000292. 
28. Nothwehr F, Yang J. Goal setting frequency and the use of behavioral strategies related to diet and physical activity. Health Educ Res 2007;22:532-8.

29. Shilts MK, Horowitz M, Townsend MS. Goal setting as a strategy for dietary and physical activity behavior change: a review of the literature. Am J Health Promot 2004;19:81-93.

30. Kabaroff JL, Eys MA, Schinke RJ, et al. The analysis of a groupmediated cognitive-behavioral corporate physical activity intervention. Work 2013;44:423-33.

31. Estabrooks PA, Nelson CC, Xu S, et al. The frequency and behavioral outcomes of goal choices in the self-management of diabetes. Diabetes Educ 2005;31:391-400.

32. Bandura A, Cervoni C. Self-evaluative and self-efficacy mechanisms governing the motivational effects of goal setting. $J$ Pers Soc Psychol 1983:45:1017-28.

33. Alm M, Soroudi N, Wylie-Rosett J, et al. A qualitative assessment of barriers and facilitators to achieving behavior goals among obese inner-city adolescents in a weight management program. Diabetes Educ 2008;34:277-84.

34. Ferrer RL, Cruz I, Burge S, et al. Measuring capability for healthy diet and physical activity. Ann Fam Med 2014;12:46-56.

35. Petrella RJ, Lattanzio CN, Shapiro S, et al. Improving aerobic fitness in older adults: effects of a physician-based exercise counseling and prescription program. Can Fam Physician 2010;56: e191-200.

36. Mauro M, Taylor V, Wharton S, et al. Barriers to obesity treatment. Eur J Intern Med 2008;19:173-80.

37. Block JP, DeSalvo KB, Fisher WP. Are physicians equipped to address the obesity epidemic? Knowledge and attitudes of internal medicine residents. Prev Med 2003;36:669-75.

38. Wadden TA, Anderson DA, Foster GD, et al. Obese women's perceptions of their physicians' weight management attitudes and practices. Arch Fam Med 2000;9:854-60.

39. Ross R, Janssen I, Dawson J, et al. Exercise-induced reduction in obesity and insulin resistance in women: a randomized controlled trial. Obes Res 2004;12:789-98.

40. Stenius-Aarniala B, Poussa T, Kvarnstrom J, et al. Immediate and long term effects of weight reduction in obese people with asthma: randomised controlled study. BMJ 2000;320:827-32.

41. Ross R, Dagnone D, Jones PJ, et al. Reduction in obesity and related comorbid conditions after diet-induced weight loss or exercise-induced weight loss in men. A randomized, controlled trial. Ann Intern Med 2000;133:92-103.
42. Office of the Chief Medical Officer of Health. New Brunswick Health Indicators Fredericton: Office of the Chief Medical Officer of Health, 2012.

43. Cramp AG, Brawley LR. Moms in motion: a group-mediated cognitive-behavioral physical activity intervention. Int J Behav Nutr Phys Act 2006;3:23.

44. Chang MW, Nitzke S, Guilford E, et al. Motivators and barriers to healthful eating and physical activity among low-income overweight and obese mothers. J Am Diet Assoc 2008;108:1023-8.

45. Brawley LR, Rejeski WJ, Lutes L. A group-mediated cognitivebehavioral intervention for increasing adherence to physical activity in older adults. J Appl Biobehav Res 2000;5:47-65.

46. Kosinski M, Kujawski SC, Martin R, et al. Health-related quality of life in early rheumatoid arthritis: impact of disease and treatment response. Am J Manag Care 2002;8:231-40.

47. Witham MD, Avenell A. Interventions to achieve long-term weight loss in obese older people: a systematic review and meta-analysis. Age Ageing 2010;39:176-84.

48. Marshall SJ, Biddle SJ. The transtheoretical model of behavior change: a meta-analysis of applications to physical activity and exercise. Ann Behav Med 2001:23:229-46.

49. Jancey J, Lee A, Howat $P$, et al. Reducing attrition in physical activity programs for older adults. J Aging Phys Act 2007;15:152-65.

50. Natarajan N, Putnam W, Van Aarsen K, et al. Adherence to antihypertensive medications among family practice patients with diabetes mellitus and hypertension. Can Fam Physician 2013;59: e93-100.

51. Vermeire $\mathrm{E}$, Hearnshaw $\mathrm{H}$, Van Royen $\mathrm{P}$, et al. Patient adherence to treatment: three decades of research. A comprehensive review. $J$ Clin Pharm Ther 2001;26:331-42.

52. Locke EA, Latham GP. Building a practically useful theory of goal setting and task motivation. A 35-year odyssey. Am Psychol 2002;57:705-17.

53. Adachi M, Yamaoka K, Watanabe M, et al. Effects of lifestyle education program for type 2 diabetes patients in clinics: a cluster randomized controlled trial. BMC Public Health 2013;13:467.

54. Walia S, Leipert B. Perceived facilitators and barriers to physical activity for rural youth: an exploratory study using photovoice. Rural Remote Health 2012;12:1842.

55. Yancey AK, McCarthy WJ, Harrison GG, et al. Challenges in improving fitness: results of a community-based, randomized, controlled lifestyle change intervention. J Womens Health (Larchmt) 2006;15:412-29. 